Original Russian Text: Iziumova A.Yu., Vshivkov A.N., Prokhorov A.E., Plekhov O.A., Venkatraman B. Study of heat source evolution during elastic-plastic deformation of titanium alloy Ti-0.8Al-0.8Mn based on contact and non-contact measurements. PNRPU Mechanics Bulletin, 2016, no. 1, pp. 68-81. DOI: 10.15593/perm.mech/2016.1.05

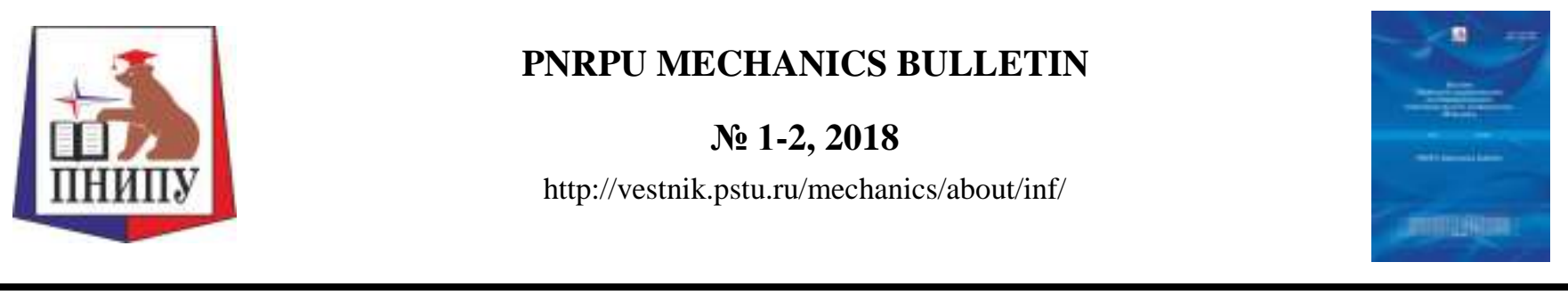

DOI: $10.15593 /$ perm.mech/eng.2018.1.10

UDC 539.424:536.62

\title{
STUDY OF HEAT SOURCE EVOLUTION DURING ELASTIC-PLASTIC DEFORMATION OF TITANIUM ALLOY OT4-0 BASED ON CONTACT AND NON-CONTACT MEASUREMENTS
}

\author{
A.Yu. Iziumova ${ }^{1}$, A.N. Vshivkov ${ }^{1}$, A.E. Prokhorov ${ }^{1}$, O.A. Plekhov¹, B. Venkatraman ${ }^{2}$ \\ ${ }^{1}$ Institute of Continuous Media Mechanics UB RAS, Perm, Russian Federation \\ ${ }^{2}$ Indira Gandhi Centre for Atomic Research, Kalpakkam, India
}

\section{ARTICLE INFO}

Received: 28.10.2015

Accepted: 25.01.2016

Published: 30.06 .2018

\section{Keywords:}

infrared thermography, contact heat flux sensor, quasistatic tension, energy dissipation, elastic-plastic deformation

\begin{abstract}
This work is devoted to investigation of the heat source evolution during quasistatic tensile testing of titanium alloy OT4-0 specimens using a contact heat flux sensor and infrared thermography. The purpose of the study is to evaluate the possibility of using two different measurement (contact and noncontact) methods to monitor the state of material by changing the heat source value registered on the specimen surface during deformation. The obvious advantages of infrared thermography are noncontact temperature measurements of the material surface under various conditions and heat source field calculations. However this method has a number of limitations associated with the reflectivity of the tested material, noisy signal caused by external factors, heat transfer conditions between the specimen and environment, and accuracy of heat source calculations. These problems do not allow using infrared thermography under operating conditions in order to evaluate the energy state of materials and structures. The paper attempts to verify the heat source value arising during the elastic-plastic deformation of the material using infrared thermography data. For this purpose, a Seebeck effect heat flux sensor has been developed by the authors. Contact sensor and infrared thermography data give time dependence of the heat flux value arising during the elastic-plastic deformation of the material. The satisfactory agreement of the results shows that contact and non-contact measurements can be used either in combination (to verify the heat source value, its distribution over the material surface and heat exchange conditions for specimen and environment) or separately (as an express method to evaluate material conditions at different stages of loading).
\end{abstract}

(C) PNRPU

${ }^{\circledR}$ Anastasia Yu. Iziumova - Junior Researcher, e-mail: fedorova@icmm.ru

Aleksei N. Vshivkov - Ph. D. student, e-mail: vshikov.a@icmm.ru

Aleksandr E. Prokhorov - Ph. D. student, e-mail: prokhorov.a@icmm.ru

Oleg A. Plekhov - Doctor of Physical and Mathematical Sciences, e-mail: poa@icmm.ru

Balasubramaniam Venkatraman - Doctor of Sciences in Computer Applications, e-mail: bvenkat@igcar.gov.in 


\section{Introduction}

Infrared thermography is a non-contact method of measuring the surface temperature of objects and is applied to monitor specimen temperature during mechanical tests [1] and to determine mechanical and thermodynamic characteristics of the material, such as fatigue limit [2, 3], critical deformation value for fast cracks [4], thermal diffusivity [5], etc. The main field of application of infrared thermography in Russia is a non-destructive testing [6].

In the last two decades, infrared thermography has been actively used to detect occurrence and development of damages (cracks, pores and other heterogeneities) of the material and to examine the process of fatigue failure. Examination of material behavior under high-cycle fatigue conditions and predicting its endurance on the basis of infrared thermography data is described in [7,8]. Williams and others [9] have shown the possibility of using infrared thermography data to forecast the fatigue life capability of welded joints.

Based on infrared thermography data, a number of problems are solved which allows determining energy characteristics of the material, such as dissipation speed and energy storage during deformation [10-14]. Estimation of different energy values (e.g. plastic/ accumulated/dissipated energies) involved in the material deformation process plays an important role for several reasons. First, measurement of these values allows a deeper examination of the mechanisms of deformation and destruction. Second, the energy concept describes changes of the material internal energy and thus contributes to development and validation of models based on thermodynamics principles. Third, information on the evolution of various energy parameters can be used for identification of coefficients (e.g. the Taylor-Quinney coefficient), often used in numerical simulation of adiabatic processes for estimation of the amount of plastic work of deformation transformed into thermal energy [15].

The obvious advantages of infrared thermography are non-contact temperature measurements of the material surface under various conditions and heat source field calculations on the specimen surface. However this method has a number of limitations associated with the reflectivity of the tested material, noisy signal caused by external factors, heat transfer conditions between the specimen and environment, and accuracy of heat source calculations. These problems do not allow using infrared thermography under operating conditions in order to evaluate the energy state of materials and structures. The paper attempts to verify the heat source value arising during the elastic-plastic deformation of the material using infrared thermography data. For this purpose, a Seebeck effect heat flux sensor [16] has been developed by the authors.

\section{Materials and Conditions of the Experiment}

A series of titanium alloy OT4-0 specimens were tested. The geometry of the specimens complied with GOST 1497-84, sizes of the specimens are shown in Fig. 1. Table 1 gives the chemical composition of the specimens.

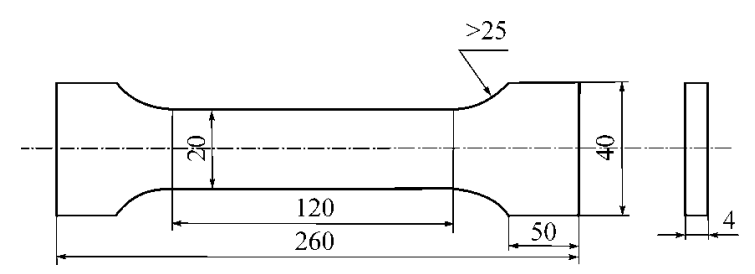

Fig. 1. Specimen geometry. Unit: $\mathrm{mm}$

Table 1

Chemical composition of titanium alloy OT4-0, \%

\begin{tabular}{|c|c|c|c|c|c|c|c|c|}
\hline \multicolumn{9}{|c|}{ Ti: base, ${ }^{*}$ : additives } \\
\hline $\begin{array}{l}\text { Chemical } \\
\text { element }\end{array}$ & $\mathrm{AL}$ & $\mathrm{Mn}$ & $\mathrm{Zr} *$ & $\mathrm{Si}^{*}$ & $\mathrm{Fe}$ & $\mathrm{C}^{*}$ & $\mathrm{AL}$ & $\mathrm{O}_{2}{ }^{*}$ \\
\hline $\begin{array}{l}\text { Requirements } \\
\text { of OST1- } \\
90013-81\end{array}$ & $\leq 1.4$ & $\leq 1.3$ & $\leq 0.30$ & $\leq 0.15$ & $\leq 1.5$ & $5 \leq 0.10$ & $\leq 1.4$ & $\leq 0.18$ \\
\hline Actual value & 1.1 & 0.9 & 0.3 & 0.004 & 1.12 & $\begin{array}{lll}2 & 0.008\end{array}$ & 1.1 & 0.082 \\
\hline \multicolumn{9}{|c|}{ Ti: base, ${ }^{*}$ : additives } \\
\hline $\begin{array}{l}\text { Chemical } \\
\text { element }\end{array}$ & $\mathrm{N}_{2}{ }^{*}$ & \multicolumn{2}{|c|}{$\mathrm{H}_{2}{ }^{*}$} & \multicolumn{2}{|c|}{$\begin{array}{l}\Sigma \text { of other } \\
\text { elements }\end{array}$} & $\mathrm{Cr}+\mathrm{Mn}^{*}$ & \multicolumn{2}{|c|}{$\mathrm{Cu}+\mathrm{Nr}^{*}$} \\
\hline $\begin{array}{l}\text { Requirements } \\
\text { of OST1- } \\
\text { 90013-81 }\end{array}$ & $\leq 0.05$ & \multicolumn{2}{|c|}{$\leq 0.015$} & \multicolumn{2}{|c|}{$\leq 0.30$} & $\leq 0.15$ & \multicolumn{2}{|c|}{$\leq 0.10$} \\
\hline Actual value & 0.012 & \multicolumn{2}{|c|}{0.003} & \multicolumn{2}{|l|}{0.022} & - & \multicolumn{2}{|c|}{0.020} \\
\hline
\end{tabular}

Specimen preparation was divided into two stages. First, the surface of specimens prepared for infrared recording was polished with abrasive paper (at the final stage of polishing the size of abrasive particles did not exceed $20 \mu \mathrm{m}$ ), and covered with a thin layer of amorphous carbon. The surface of specimens intended for mounting the contact heat flux sensor did not require additional preparation. Before testing, marks were attached to this surface to record movement during the mechanical test. Thermal paste was applied on the specimen surface under heat flux sensor to provide a good thermal contact. Fig. 2 shows the scheme of the experimental assembly which includes electric mechanical testing machine Shimadzu AGX Plus $(300 \mathrm{kN})$, contact heat flux sensor, IR camera FLIR SC5000, and video extensometer Shimadzu TRViewX240S. IR camera has the following features: spectral range of 3-5 $\mu \mathrm{m}$, maximum picture size of $320 \times 256$ pixels, spatial sensitivity of $10^{-4} \mathrm{~m}$, minimum temperature measurement error of $25 \mathrm{mK}$ at a specimen temperature of $300 \mathrm{~K}$. To exclude the influence of internal sources and artifactual rereflections, the system was covered by a screen after placing the specimen in the test machine grips. IR data recording as well as recording of the heat flow sensor data mounted on the specimen were carried out continuously during the entire mechanical test. IR data recording frequency was $25 \mathrm{~Hz}$. 


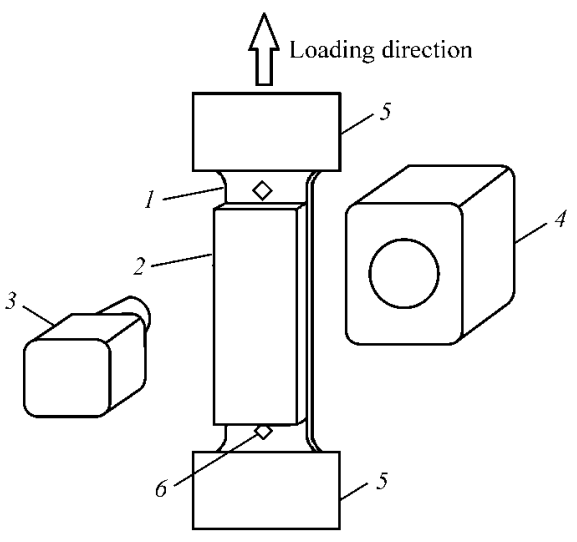

Fig. 2. Scheme of the experimental assembly for energy balance analysis in materials under quasistatic tensile conditions:

1 - specimen, 2 - contact heat flux sensor, 3 - video camera for recording marks displacement, 4 - IR camera, 5 - grips of the testing machine, 6 - marks for movement detection

The contact heat flux sensor was pre-calibrated. The calibration function (1) shows the relationship between the potential difference $U(\mathrm{~B})$, arising due to the temperature difference between the two surfaces of Peltier elements, that the contact heat flux sensor consists of, and power of the heat flux in $W$.

$$
W=0,006 U+0,0042 .
$$

After adjustment of all the systems and shielding the assembly for each specimen, additional experiments were carried out to determine conditions of heat exchange between the specimen and the environment. These experiments involved registration of the temperature field of the specimen surface after its pulse point heating and constructing a cooling curve with the help of which heat exchange constant was calculated. After that, mechanical tests for quasistatic tensile of flat specimens were conducted with a simultaneous registration of temperature field of the specimen surface (IR data recording), heat flux (contact sensor) and movement of the specimen working area (video extensometer). The speed of grip movements varied and was 5 and $10 \mathrm{~mm} / \mathrm{min}$ during different tests, which corresponded to the following rates of deformation: $7.7 \cdot 10^{-4} \mathrm{~s}^{-1}$ and $15 \cdot 10^{-4} \mathrm{~s}^{-1}$. Fig. 3 shows a typical specimen deformation diagram based on the video extensometer data.

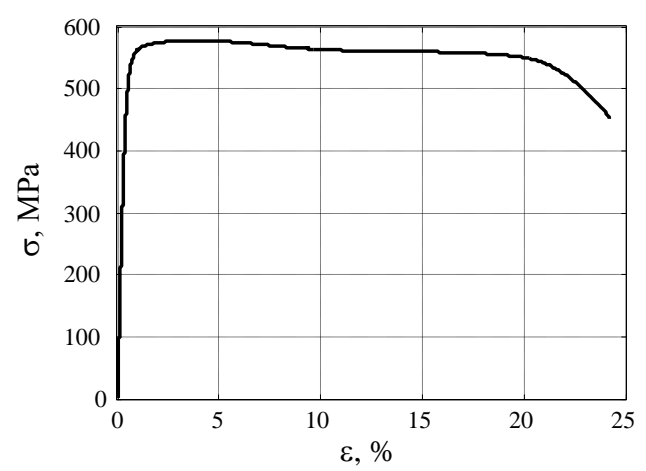

Fig. 3. Typical deformation diagram for titanium alloy OT4-0

\section{Estimation of the Heat Sources Field Based on the Heat Conductivity Equation}

Heat sources field calculation based on the infrared thermography data was carried out using the heat conductivity equation (2).

$$
\begin{gathered}
\rho c \frac{\partial T(x, y, z, t)}{\partial t}=Q(x, y, z, t)+ \\
+k\left(\frac{\partial^{2} T(x, y, z, t)}{\partial x^{2}}+\frac{\partial^{2} T(x, y, z, t)}{\partial y^{2}}+\frac{\partial^{2} T(x, y, z, t)}{\partial z^{2}}\right),
\end{gathered}
$$

where $T(x, y, z, t)$ defines temperature field, $\rho$ is material density, $c$ is heat capacity, $k$ is heat conductivity, $Q(x, y, z, t)$ is the heat sources field, $x, y, z$ are coordinates, $t$ is time.

Infrared thermography allows to record temperature field of the specimen surface. It is not possible to control the temperature distribution through the specimen thickness with this method, therefore, rather thin specimens are used in the experimental tests, and it is assumed that in this case the temperature distribution through the specimen thickness is homogeneous $[17,18]$.

Equation (2) averaged on volume basis is used for estimation of integral power of the heat source. A typical averaging procedure was conducted. The difference $\theta^{\prime}(t)$ between the specimen temperature averaged on volume basis and the initial temperature of $T_{0}$ specimen in the thermal balance with the environment is defined as in equation (3).

$\theta^{\prime}(t)=\frac{1}{V} \int_{-a / 2}^{a / 2} \int_{-b / 2}^{b / 2} \int_{-h / 2}^{h / 2}(T(x, y, z, t)-T)_{0} d x d y d z=\theta(t)-T_{0}$,

where $T_{0}$ stands for the initial temperature of the specimen in the thermal balance with the environment, $a, b, h$ is length, width and thickness of the specimen, respectively, $V$ is volume.

The boundary conditions are expressed as follows:

$$
\begin{gathered}
\left.\frac{\partial \mathrm{T}(x, y, z, t)}{\partial x}\right|_{x=\frac{a}{2}}=-\left.\frac{\partial \mathrm{T}(x, y, \mathrm{z}, t)}{\partial x}\right|_{x=-\frac{a}{2}} \\
-\left.k \frac{\partial T(x, y, z, t)}{\partial x}\right|_{x=\frac{a}{2}}=\frac{g_{x}}{a} \int_{-a / 2}^{a / 2}\left(T(x, y, z, t)-T_{0}\right) d x,
\end{gathered}
$$

where $g_{x}$ means the heat exchange coefficient between the specimen and the environment on the corresponding edge of the specimen. The boundary conditions in two other directions are similar except for the coefficients $g_{i}$, $i=\{x, y, z\}$.

By integrating the volume equation (2) considering the formula (3) and the boundary conditions (4), we shall obtain the heat conductivity equation averaged on volume basis to calculate the heat sources power field:

$$
S(t)=m c \frac{\partial \theta(\mathrm{t})}{\partial t}+\beta V\left(\theta(t)-T_{0}\right),
$$


where $\theta$ is the average temperature of the examined surface, $T_{0}$ is the initial temperature of the examined surface in thermal balance with the environment, $m$ is the mass of the area where the average temperature is taken from (the density of the titanium alloy OT4-0 $\rho$ is $4457 \mathrm{~kg} / \mathrm{m}^{3}$ $[19,20]), c$ is the specific heat (for OT4-0 $456 \mathrm{~J} /(\mathrm{kg} \cdot \mathrm{K}$ ) $[19,20]), S(t)$ is the heat sources field (W), $\beta$ is the material parameter that determines heat losses, associated with the heat exchange with the environment. The parameter $\beta$ is determined by the experiment data based on the tests related to the specimen cooling after pulse point heating.

\section{Experimental Determination of Heat Exchange Constants Between the Specimen and the Environment}

To calculate the heat sources field with the equation (5) for the experimentally obtained temperature field, it is necessary to determine $\beta$ parameter, which defines heat losses during interaction of the specimen with the environment. For this purpose additional experiments on the specimen cooling after pulse point heating were conducted. Fig. 4 shows a typical IR image made during pulse point heating of the specimen and experimental data of the average temperature of the heating area.

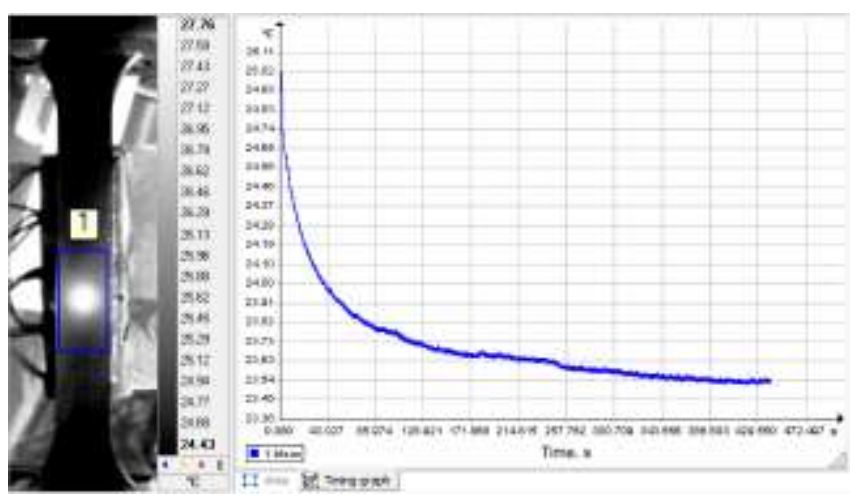

Fig. 4. Typical IR image of the specimen during pulse point heating and heating area average temperature vs time curve

The specimen cooling after pulse point heating can be described by the averaged thermal conductivity equation (5) with zero source strength:

$$
0=m c \frac{\partial \theta(t)}{\partial t}+\beta V\left(\theta(t)-T_{0}\right) .
$$

Solution of this equation is the following function:

$$
\theta(t)=C_{1} e^{-\frac{\beta}{\rho c} t}+C_{2}
$$

where $C_{1}$ and $C_{2}$ are constants, $\rho$ is the density.

To calculate the constant $\beta$, it is necessary to approximate the experimental data of the average specimen temperature after pulse point heating. As an approximating function, we shall choose the following one:

$$
y(x)=A e^{-B x}+C .
$$

In order to find the parameter of heat exchange between the specimen and the environment, only linear in semilogarithmic coordinates part of the curve of the specimen cooling after pulse point heating (green line in Fig. 5) is approximated, this is the part that corresponds to the exponential dependence of temperature on time (7).

The parameter $\beta$ depends on the environmental conditions and is not a constant value for this material; therefore it must be determined directly before mechanical tests. Table 2 shows the typical data obtained for one of the tested specimens: product of density and thermal conductivity taken from the reference data $[19,20]$, experimentally obtained value of the exponent $B$ from the equation (8) and parameter $\beta$ calculated based on these values.

Table 2

Result of approximation of the specimen cooling curve

\begin{tabular}{|c|c|c|c|}
\hline $\begin{array}{c}\text { Test } \\
\text { No. }\end{array}$ & $\begin{array}{c}\text { Product of density and thermal } \\
\text { conductivity } \rho \mathrm{c}, \mathrm{J} /\left(\mathrm{m}^{3} \mathrm{~K}\right)\end{array}$ & $\begin{array}{c}\text { Exponent } \\
\text { degree in the } \\
\text { approximation } B\end{array}$ & $\beta$ \\
\hline 1 & $2.04 \cdot 10^{6}$ & 0.0080 & $1.632 \cdot 10^{4}$ \\
\hline 2 & $2.04 \cdot 10^{6}$ & 0.0061 & $1.239 \cdot 10^{4}$ \\
\hline 3 & $2.04 \cdot 10^{6}$ & 0.0065 & $1.331 \cdot 10^{4}$ \\
\hline \multicolumn{2}{r}{} & Average value & $1.4 \cdot 10^{4}$ \\
\cline { 2 - 4 }
\end{tabular}

As a result, based on the above procedure an experiment on the specimen cooling after pulse point heating was performed and the values of the parameter $\beta$ for each specimen before its deformation were calculated.

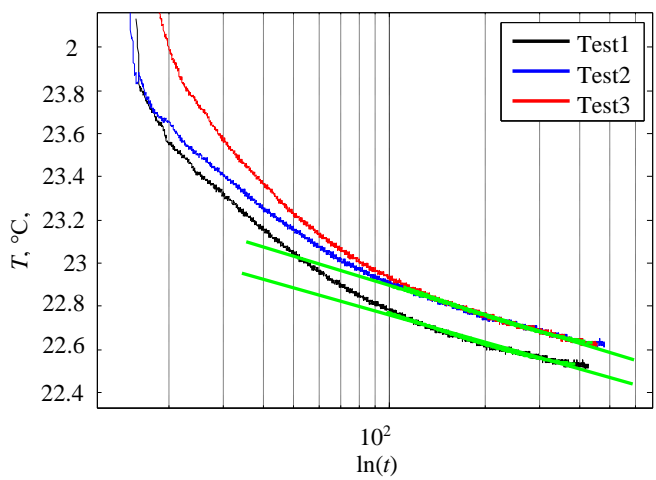

Test 1:

$\mathrm{T}=0.27 \mathrm{e}^{0.0080}+22.51$

Test 2:

$\mathrm{T}=0.3 \mathrm{e}^{0.0061}+22.59$

Test 3:

$\mathrm{T}=0.29 \mathrm{e}^{0.0065}+22.6$

Fig. 5. Approximation of the part curve of the specimen cooling after pulse point heating 


\section{Experimental Determination of the Integral Heat Source Value Based on the Infrared Thermography Data}

Fig. 6 shows the typical IR image of the specimen surface at the final stage of deformation before destruction and experimental dependence of the average temperature of the selected area on the mechanical test duration. At the beginning the average surface temperature of the specimen drops due to the thermoelastic effect, then the thermoplastic effect prevails, and the average temperature of the specimen starts to increase up until the moment of necking and complete destruction.

Dependence of the heat source field on time was defined with the formula (5) based on the change of the specimen temperature during the mechanical test and experimentally obtained value of the parameter $\beta$.

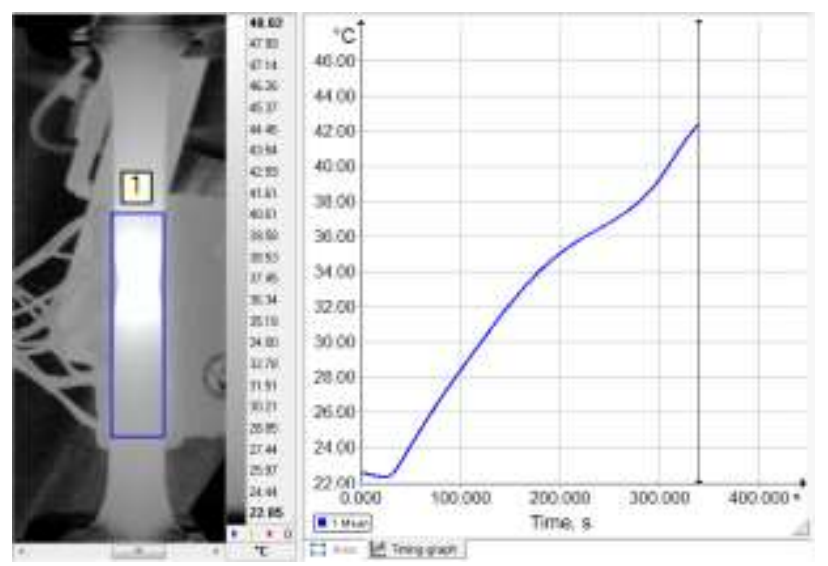

Fig. 6. Typical IR image of the specimen under quasistatic tensile conditions before destruction and heating area average temperature vs time curve

Based on data given in Table 2, fluctuations of the parameter $\beta$ are about $30 \%$. Fig. 7 shows a characteristic change of the heat source field over time and the confidence interval. At the beginning of loading (0-70 s) fluctuations of the parameter $\beta$ almost did not influence the value of the heat source field. The influence of the parameter $\beta$ becomes significant from the 70-th second. During this period of the time maximum value of the standard deviation of the heat source field (calculated at an average value of $\beta$ ) is 0.27 .

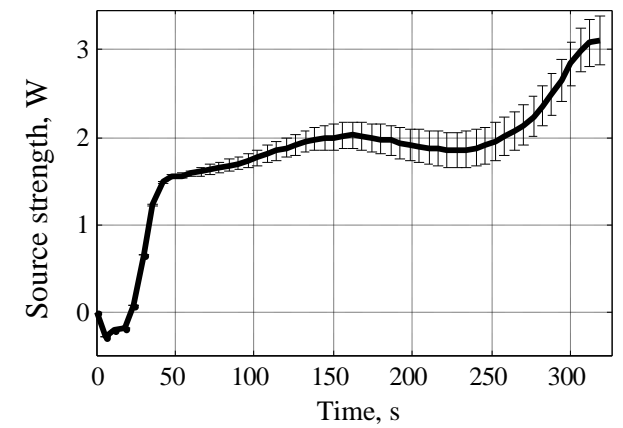

Fig. 7. Value of the heat source field calculated using the infrared thermography data at the average value of $\beta$ and the confidence interval
Fig. 8 and 9 show the dependence of the average temperature of the specimen surface, calculated heat sources field and applied load on time for two strain rates: $7.7 \cdot 10^{-4}$ and $15 \cdot 10^{-4} \mathrm{~s}^{-1}$.

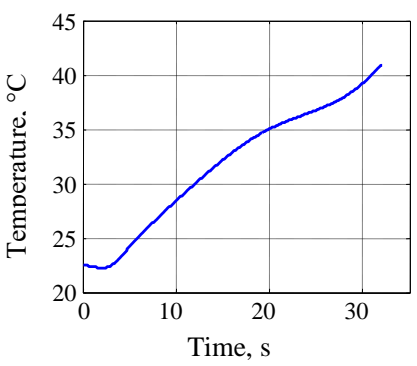

$a$

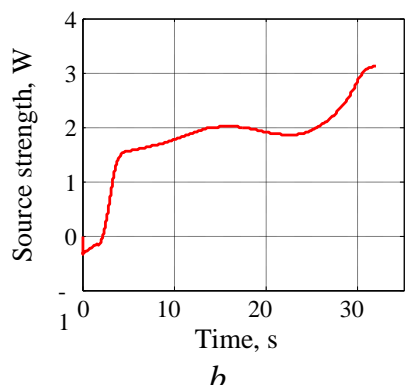

$b$

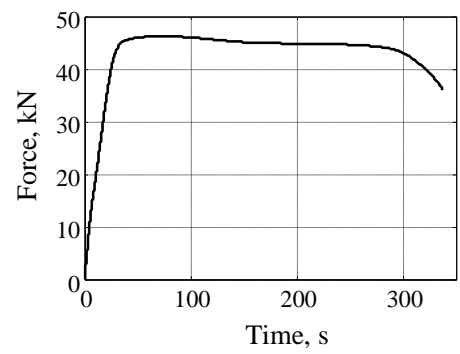

$c$

Fig. 8: $a$-typical dependence of the average temperature on time under quasistatic tensile conditions; $b$ - corresponding dependence of integral quantity of the heat source field on time based on the infrared thermography data; $c$ - load diagram. Strain rate of $7.7 \cdot 10^{-4} \mathrm{~s}^{-1}$

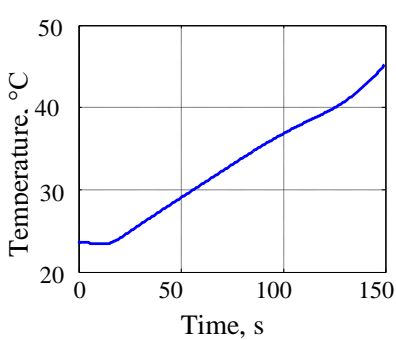

$a$

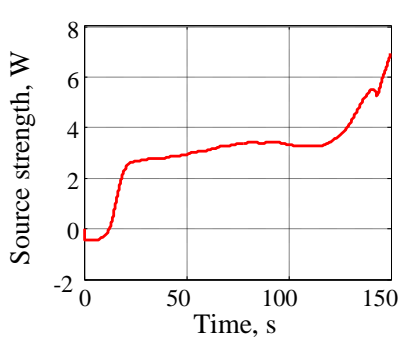

$b$

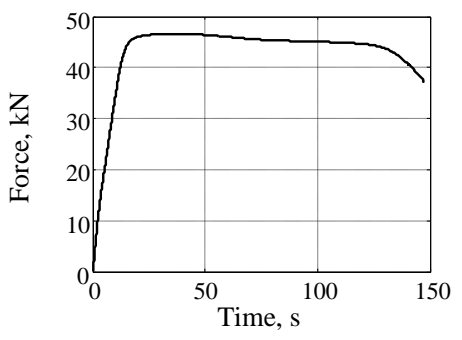

c

Fig. 9: $a$ - atypical dependence of the average temperature on time under quasistatic tensile conditions; $b$ - the corresponding dependence of the integral quantity of the heat source field on time based on the infrared thermography data; $c$ - load diagram. Strain rate is $15 \cdot 10^{-4} \mathrm{~s}^{-1}$

According to the defined dependences the heat flux becomes almost constant between $40 \mathrm{~s}$ and $250 \mathrm{~s}$ at a strain rate of $7.7 \cdot 10^{-4}$ and between $25 \mathrm{~s}$ and $120 \mathrm{~s}$ at a strain rate of $15 \cdot 10^{-4}$. At this point one can see a yield line and a mild softening on the load diagram. By the time of necking the heat flux increases abruptly, which indicates the material destruction. 


\section{Results Comparison and Conclusions}

The heat flux sensor was continuously recording values of the heat source field in the specimen area where it was mounted. Such a possibility to record the integrated flux is one of the advantages of the developed sensor, which allows monitoring the energy state of the material in situ. Fig. 10 shows typical diagrams of the heat source field change during mechanical tests at different strain rates. These diagrams are drawn with the heat flux sensor using infrared thermography data (non-contact method of temperature recording).
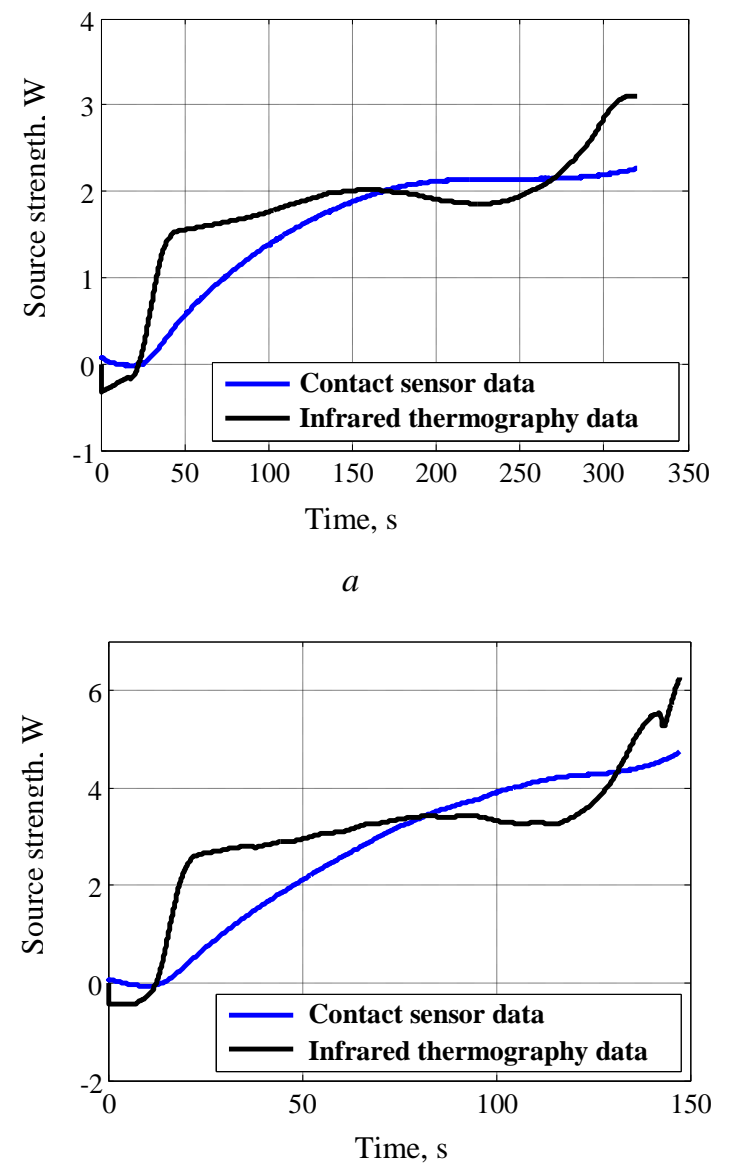

$b$

Fig. 10. Infrared thermography data vs heat flux sensor data: $a$ - strain rate of $7.7 \cdot 10^{-4} \mathrm{~s}^{-1}, b-$ strain rate of $15 \cdot 10^{-4} \mathrm{~s}^{-1}$

Infrared thermography shows higher sensitivity to heat flux changes, than the contact measurement method, but requires a considerable amount of time for data processing, considering the conditions of heat exchange and determination of the parameter $\beta$, and calculating the heat source field using the difference scheme of equation (5). On the other hand, when a contact sensor records continuously the integral quantity of the heat flux, it does not allow estimating the space distribution of sources and monitoring the location of the material plastic deformation. The noncomplete correspondence of the heat flux data of the two methods can be explained by different sensitivities of the devices, errors of numerical processing of the infrared thermography data and determination of the heat exchange parameter between the specimen and the environment. The issue of thermal inertia of the contact sensor is still open. The article [21] provides information on the sensor values accuracy at a changing heat flux caused by a low power source. For high heat flux values the sensor inertia should be more noticeable and last for several seconds. This problem requires further research and creation of additional algorithms for data processing. However the obtained results show that contact and non-contact measurements can be used either in a combination (to verify the heat source value, its distribution over the material surface and heat exchange conditions for specimen and environment) or separately (as an express method to evaluate material conditions at different stages of loading).

The project is developed with the financial support of the Russian Foundation for Basic Research (Grant No. 16-51-48003 and 14-01-00122).

\section{References}

1. Vshivkov A.N., Prokhorov A.E., Uvarov S.V., Plekhov O.A. Osobennosti mekhanicheskogo povedeniia armko-zheleza pri ispytanii $\mathrm{v}$ rezhime gigatsiklovoi ustalosti [Peculiarities of mechanical behavior of armco-iron under fatigue in gigacyclic regime]. PNRPU Mechanics Bulletin, 2014, No. 4, pp. 18-32.

2. La Rosa G., Risitano A. Thermographic methodology for rapid determination of the fatigue limit of materials and mechanical components. International Journal of Fatigue, 2000, Vol. 22, pp. 65-73. DOI: 10.1016/S0142-1123(99)00088-2

3. Terekhina A.I., Fedorova A.Yu., Bannikov M.V., Plekhov O.A. Razrabotka metoda otsenki predela vynoslivosti materiala po dannym infrakrasnoi termografii [A development of a method for estimation of the endurance limit of the material using infrared thermography data] // PNRPU Mechanics Bulletin, 2012, No. 4, pp. 115-127.

4. Sony Punnosen, Amretendu Mukhopadhyay, Rajdeep Sarkar, Zafir Alam, Dipak Das, Vikas Kumar. Determination of critical strain for rapid crack growth during tensile deformation in aluminide coated near- $\alpha$ titanium alloy using infrared thermography. Materials Science \& Engineering, 2013, Vol. A 576, pp. 217-221. DOI: 10.1016/j.infrared.2015.09.021

5. Huilong Dong, Boyu Zheng, Feifan Chen. Infrared sequence transformation technique for in situ measurement of thermal diffusivity and monitoring of thermal diffusion. Infrared Physics \& Technology, 2015, Vol. 73, pp. 130-140. DOI: 10.1016/j.infrared.2015.09.021

6. Vavilov V.P. Noise-limited thermal/infrared nondestructive testing. NDT \& E International, 2014, Vol. 61, pp. 16-23. DOI: 10.1016/j.ndteint.2013.09.002

7. Zhang H.X., Wu G.H., Yan Z.F., Guo S.F., Chen P.D., Wang W.X. An experimental analysis of fatigue behavior of AZ31B magnesium alloy welded joint based on infrared thermography. Materials and Design, 2014, Vol. 55, pp. 785-791. DOI: 10.1016/j.matdes.2013.10.036

8. Wang X.G., Crupi V., Guo X.L. and Zhao Y.G. Quantitative Thermographic Methodology for fatigue assessment 
and stress measurement. International Journal of Fatigue, 2010, Vol. 32, No. 12, pp. 1970-1976. DOI: 10.1016/j.infrared.2015.06.003

9. Williams P., Liakat M., Khonsari M.M., Kabir O.M. A thermographic method for remaining fatigue life prediction of welded joints. Mater Des, 2013, Vol. 51, pp. 916-23. DOI: $10.1016 /$ j.infrared.2015.06.003

10. Adil Benaarbiaa, André Chrysochoos, Gilles Robert. Kinetics of stored and dissipated energies associated with cyclic loadings of dry polyamide 6.6 specimens. Polymer Testing, 2014, Vol. 34, pp. 155-167. DOI: 10.1016/j.polymertesting.2014.01.009

11. Srinivasan Nagarajan, Raghu Narayanaswamy, Venkatraman Balasubramaniam. Study on the kinetics of thermomechanical response accompanying plastic instability in mild steel. Mechanics of Materials, 2015, Vol. 80, pp. 27-36. DOI: 10.1016/j.mechmat.2014.09.004

12. Oliferuk W., Maj M., Zembrzycki K. Determination of the Energy Storage Rate Distribution in the Area of Strain Localization Using Infrared and Visible Imaging. Experimental Mechanics, 2015, Vol. 55, pp. 753-760. DOI: 10.1007/s11340-013-9819-1

13. Ivanov A.M., Lukin E.S. Investigation of the stored energy change of steel Fe360 subjected to equal-channel angular pressing. Materials Science and Engineering, 2009, Vol. A 503, pp. 45-47. DOI:10.1016/j.msea.2008.02.054

14. Fedorova A., Bannikova M., Terekhina A., Plekhov O. Heat dissipation energy under fatigue based on infrared data processing. Qualitative Infrared Thermograthy Journal, 2014, Vol. 11, Is. 1, pp. 2-9. DOI: 10.1080/17686733.2013.852416

15. Dumoulin S., Louche H., Hopperstad O.S., Borvik T. Heat sources, energy storage and dissipation in high-strength steels: experiments and modeling. European Journal of Mechanics A/Solids, 2010, Vol. 29, pp. 461-474. DOI: 10.1016/j.euromechsol.2009.11.005

16. Vshivkov A.N. Issledovanie kinetiki rosta ustalostnykh treshchin $\mathrm{v}$ metallakh s pomoshch'iu kontaktnogo datchika potoka tepla [The study of fatigue crack growth kinetics in metals by contact heat flux sensor]. XI Vserossiiskii s"ezd po fundamental'nym problemam teoreticheskoi $i$ prikladnoi mekhaniki: sbornik trudov (All-Russian Congress of the fundamental problems of theoretical and applied mechanics: a collection of papers), Kazan, 2015, pp. 824-827.

17. Boulanger T., Chrysochoos A., Mabru C., Galtier A. Calorimetric analysis of dissipative and thermoplastic effects associated with the fatigue behavior of steel. International journal of fatigue, 2004, Vol. 26, pp. 221-229. DOI: 10.1016/S0142-1123(03)00171-3

18. Chrysochoos A., Louche H. An infrared image processing to analyse the calorific effects accompanying strain localization. International journal of engineering science, 2000, Vol. 38, pp. 1759-1788. DOI: 10.1016/S0020-7225(00)00002-1

19. Peletskii V.E. Teplofizicheskie svoistva titana i ego splavov [Thermal properties of titanium and its alloys]. Moskow, Metallurgiia, 1985, $103 \mathrm{p}$.

20. Iu.M. Lakhtin. Metallovedenie i termicheskaia obrabotka metallov [Metallurgy and heat treatment of metals]. Moskow, Metallurgiia, 1983, $359 \mathrm{p}$.

21. Vshivkov A., Iziumova A., Bar U., Plekhov O. Experimental study of heat dissipation at the crack tip during fatigue crack propagation. Fracture and Stractural Integrity, 2016, Vol. 35, pp. 131-137. 